\title{
Need analysis for the development of a microcontroller instructional module programming literacy
}

\author{
Yusriza Mohamad Yusof ${ }^{1}$, Afida Ayob ${ }^{2}$, Mohamad Hanif Md Saad ${ }^{3}$, Haryanti Mohd Affandi ${ }^{4}$, \\ Aini Hussain ${ }^{5}$ \\ ${ }^{1,2,3,5}$ Centre for Integrated Systems Engineering and Advanced Technologies (INTEGRA), \\ Department of Electrical, Electronics and Systems Engineering, \\ Faculty of Engineering and Built Environment, The National University of Malaysia, Malaysia \\ ${ }^{4}$ Engineering Education Research Center, Faculty of Engineering and Built Environment,
} The National University of Malaysia, Malaysia

\section{Article Info}

Article history:

Received Oct 30, 2019

Revised Dec 28, 2019

Accepted Jan 24, 2020

\section{Keywords:}

Design and development research (DDR)

Instructional module

Raspberry Pi

\begin{abstract}
In the era of the IR 4.0, the use of information technology among school students is widespread but students are not proficient in computer programming. To compete in the digital world, students need to be exposed to computer programming in order to produce computer programming experts. Integrating computer programming into the school curriculum can improve students literacy of computer programming but adequate computer programming skill among teachers are quite limited. Therefore, the development of microcontroller instructional teaching module which could address this problem is needed. This development aims to develop the module using design and developmental research (DDR) approach. Need analysis phase in DDR is discussed in this article. The phase consists of identifying the level of knowledge, attitudes and practices of teachers about microcontroller and to obtain the views and opinions of the teachers on the developmental needs of microcontroller teaching modules. The type of microcontroller and the programming language to be used in the microcontroller module also identified. The results of this study are important to ensure that the design and development of an instructional module for microcontroller education are implemented and have a positive impact on increasing the programming literacy level among secondary school children.
\end{abstract}

This is an open access article under the CC BY-SA license.

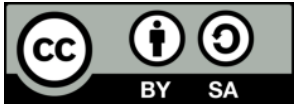

\section{Corresponding Author:}

Afida Ayob,

Centre for Integrated Systems Engineering and Advanced Technologies (INTEGRA),

Faculty of Engineering and Built Environment, Universiti Kebangsaan Malaysia,

43600 UKM Bangi,Selangor, Malaysia.

Email: afida.ayob@ukm.edu.my

\section{INTRODUCTION}

Programming is an important new literacy in todays digital age. Microcontroller programming is a basic skill required to learn robotics which is compulsory to ensure quality and continuous improvement in these fields [1]. However in Malaysia, microcontroller subjects are only taught to undergraduate electronic engineering students [2]. Therefore the Ministry of Education Malaysia has taken the responsibility to include microcontroller education in the secondary school curricular as a kick start for secondary school students to enhance their interests in the robotic world as stated in the Malaysia Education Blueprint [3]. The Ministry of Education Malaysia integrates STEM education in all subjects with the implementation of Primary School Standard Curriculum (Kurikulum Standard Sekolah Rendah (KSSR)) pioneered 
by standard 4 students in 2014 and continues with Secondary School Standard Curriculum (Kurikulum Standard Sekolah Menengah (KSSM)) in 2017.

Design and Technology (Reka Bentuk dan Teknologi-RBT) subjects were implemented in KSSR and KSSM to replace Integrated Living Skills (Kemahiran Hidup Bersepadu-KHB) subject and microcontroller is one of the topics in RBT for form 2 secondary school students. Basic programming using blocks like Scratch was taught to standard 6 primary school students starting from 2016. Besides lacking in hands-on tools and modules used in microcontroller lessons, lack of expert teachers in this subject area and complete laboratory facilities are constraints for teachers to deliver microcontroller topics in RBT subject effectively. InMalaysia, secondary school students aged between 13 to 17 years old are split into two categories, lower and upper secondary school students. Other countries uses different range of ages and terms to describe secondary school ages [4]. In Japan, junior school age is between 12 to 15 years old [5].

Microcontroller topic in the RBT subjects, requires students to achieve defined learning standards. These learning standards are fundamental for microcontroller lessons. Basic programming language using block programming like Scratch is included in RBT subject for primary schools. Learning robotic in secondary schools nurturestudents interest about the robotic world and students can apply the knowledge in all subjects related to science [6]. Previous research has shown that learning by doing or project-based learning could increase students' eagerness to STEM education [7]. Implementing engineering elements such as robotics elements in teaching and learning could construct students interest towards robotic because engineering furnish a platform for students to associate science with their daily experiences [8]. Teaching robotics is an interesting ways to foster secondary school with microcontroller education and programming [9].

Students prefer to learn programming using robotics as a platform rather than using special programming software [8]. Learning programming using approaches like Scratch, mBlock, Pyhthon IDLE is more of a cognitive activity. Learning programming can be enhanced by using microcontroller platforms to visualize the output of the programming. This method can incorporate psychomotor activities among students. Therefore, the development of a Microcontroller Instructional Module is essential to help teachers conduct teaching and learning more effectively to enhance student interest. This paper presents the need analysis for the development of a microcontroller instructional module for programming literacy.

\section{RESEARCH METHODOLOGY}

Design and development of microcontroller instructional teaching module adapt the design and developmental research (DDR) founded by Rita Klein and James D Klein in 2007 [10]. DDR is a systematic study of the design, development and evaluation of processes with the aim of empirically establishing the creation of teaching products rather than teaching products or tools and enhancements of existing models and their developers. DDR is a flexible form of study in answering research questions. It involves a variety of approaches analysis and more systematic based on specific phases. DDR approach consist of three phases: 1) need analysis, 2) design and development, and 3) evaluation. The sample, instrument and data analysis of each phase differ. In this paper, only the first phase of the whole research cycle will be discussed.

This paper is organized only to present the first phase of DDR used to develop the microcontroller instructional teaching module. Figure 1 shows the phases of DDR. Phase 1 of DDR is the need analysis of development requirements for microcontroller instructionalteaching modules. The study would center on the following research objectives:

a. to identify the level of knowledge, attitudes and practices of teachers for microcontroller topic,

b. to obtain the views and opinions of the teachers on the developmental needs of microprocessor teaching modules, and

c. to identify the type of microcontroller and the programming language to be used in the microcontroller module to be developed.

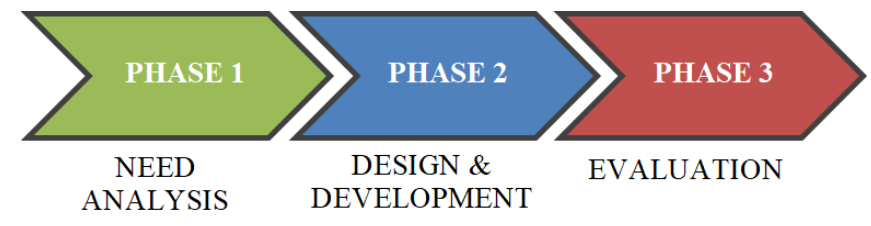

Figure 1. Phase of DDR [10] 


\subsection{Participant and sample of the study}

Respondents of the questionnaire were selected randomly between Form 2 RBT teachers of secondary schools in Selangor teaching the RBT subject within 3 years since 2017 when RBT was first introduced under KSSM. A total of 32 secondary schools in the state of Selangor were chosen to participate in this survey involving 105 Form 2 RBT teachers. The questionnaire developed by the researcher has been verified by several experts in the field of module development, language and technical content. An open-ended questionnaire also conducted on 52 respondents consisting of Form 2 RBT teachers. This survey was conducted throughout September 2019 via online method.

\subsection{Instrument}

This study uses a mix method research design of data collection. Questionnaire with several close ended question using 5 Likert Scale and one open ended question are used in order to explore the level of knowledge, attitudes and practices of the respondents. Then using triangulation, which bringing together complementary methods or data sources to offset weaknesses in each research method [11]. An open ended question isused to give the respondent the opportunity to spell out their opinion about developing the microcontroller instructional teaching module. The 5 Likert Scale of agreement used in this survey questions is stated as $1=$ strongly disagree; 2 =disagree; $3=$ uncertain; $4=$ agree and 5=strongly agree.

\subsection{Data analysis}

The findings of this study were analyzed descriptively using IBM SPSS Statistics computing software version 25.0 to determine their knowledge, attitudes and practices about microcontroller and give their opinion on developing the microcontroller instructional teaching module.

\subsection{Validity of the questionnaire}

Prior to the actual questionnaire, a pilot study was conducted on 30 respondents for validity of the instrument [12]. The validity of the questionnaire can be done in two ways: (a) the validity of the construct through several designated experts and (b) reliability coefficient of each construct in the questionnaire.

\subsubsection{Validity of the questionnaire constructs}

The validity of the questionnaire was verified by several designated experts in module development, language and technical contents [13]. All the experts appointed agree on face validity, content validity and construct validity.

\subsubsection{Reliability coefficient (Cronbach'salpha)}

Reliability coefficient was seen to determine the level of confidence of the respondents to the questionnaire [13]. Reliability refers to the consistency of the results that obtain from the assessment [14]. Realiability Coefficient or Cronbach's Alpha formula stated as below:

$$
\frac{\mathrm{N} \cdot \overline{\mathrm{c}}}{\overline{\mathrm{V}}+(\mathrm{N}-1) \cdot \overline{\mathrm{C}}}
$$

where: $\mathrm{N}=$ the number of items

$\overline{\mathrm{c}}=$ average covariance between item-pairs

$\overline{\mathrm{v}}=$ average variance

By looking at Table 1, the finding indicates that Cronbach Alpha for all construct were above 65. Reliability coefficients can take one value from -0.1 to +1.0 . High alpha $(\alpha)$ value index scores $\alpha=65$ to 95 indicates the questionnaire have high reliability [13].

Table 1. Reliability coefficients for each section of the questionnaire

\begin{tabular}{ccc}
\hline Construct & No. of item & Cronbach's Alpha \\
\hline Knowledge & 7 & .889 \\
Attitudes & 6 & .715 \\
Practise & 8 & .725 \\
Module development & 8 & .832 \\
\hline
\end{tabular}




\section{RESULTS AND ANALYSIS}

\subsection{Demographic profile of respondent}

This section presents the overall dimension of respondents' profile, which in particular describes their gender, age, level of education and experience teaching in design and technology subject. The first frequency test looks at respondents' gender. Tables 2-5 show the results. $90.5 \%$ of the respondents were female RBT teachers. Majority of respondent are at the age between 31-40 years old. Most of the respondents have at least a university degree for their level of education.

Table 2. Numbers of overall respondents by gender

\begin{tabular}{ccc}
\hline Gender & Frequency & Percentage \\
\hline Male RBT teachers & 10 & 9.5 \\
Female RBT teachers & 95 & 90.5 \\
Total & 105 & 100.0 \\
\hline
\end{tabular}

Table 3. The number of overall respondents by age

\begin{tabular}{ccc}
\hline Age & Frequency & Percentage \\
\hline $21-30$ & 10 & 9.5 \\
$31-40$ & 66 & 62.9 \\
$41-50$ & 21 & 2.0 \\
$51-60$ & 8 & 7.6 \\
Total & 105 & 100.0 \\
\hline
\end{tabular}

Table 4. Numbers of overall respondents by their level of education

\begin{tabular}{ccc}
\hline Level of education & Frequency & Percentage \\
\hline Diploma & 3 & 2.9 \\
Degree & 97 & 92.4 \\
Master & 5 & 4.8 \\
PhD & 0 & 0 \\
Total & 105 & 100.0 \\
\hline
\end{tabular}

Table 5. Numbers of overall respondents by their experience teaching RBT subjects

\begin{tabular}{ccc}
\hline Month & Frequency & Percentage \\
\hline 1-6 months & 13 & 12.4 \\
7-12 bulan & 20 & 19.0 \\
$13-18$ months & 19 & 18.1 \\
19-24 months & 28 & 26.7 \\
25-30 months & 10 & 9.5 \\
31 months and above & 15 & 14.3 \\
Total & 105 & 100.0 \\
\hline
\end{tabular}

\subsection{Level of knowledge, attitudes and practices of teachers for microcontroller in their teaching}

Table 6 shows descriptive statistics of knowledge, attitudes, practice as well as module development needs. Through the analysis, knowledge, attitudes, practices of form 2 RBT teachers towards teaching and learning in the topic of electronic design were studied. Based on Table 6, when referring to mean values $=3.03$, it shows that teachers are uncertain about their knowledge in electronic design. Standard deviation values show the spread of the data from mean value [15]. Data distribution for knowledge is relatively small which is around 0.684 from the mean value. This indicates that standard deviation value for teachers' attitudes and practices are smaller than standard deviation value of teachers' knowledge in electronic design. The mean values of attitudes and practices are 3.74 and 3.67. The standard deviations are 0.367 for attitude and 0.366 for practice and it indicates that the mean values of attitudes and practice are around 3 and 4 which is less dispersed from the mean values. It indicates that several respondents are unsure about their attitude and practice of microcontroller in their teaching and others agree on it. Mean value for module development needs is 4.42 and the standard deviation is 0.485 . Again, this indicates that the mean value for module development is less dispersed from the mean value. From these values we conclude that there is a need to develop the instructional module of microcontroller for electronic design topic. 
Table 6. Descriptive statistics of knowledge, attitudes, practices and module development needs of form 2 RBT teachers

\begin{tabular}{lccccc}
\hline & $\mathrm{N}$ & Minimum & Maximum & Mean & Std. Deviation \\
\hline Knowledge & 105 & 1 & 4 & 3.03 & .684 \\
Attitudes & 105 & 3 & 5 & 3.74 & .367 \\
Practices & 105 & 3 & 5 & 3.67 & .366 \\
Module development & 105 & 3 & 5 & 4.42 & .485 \\
\hline
\end{tabular}

\subsection{Views and opinions of the teachers on the developmental needs of microprocessor teaching modules}

Based on this procedure, the researcher found that 51 out of 52 respondents who stated that they agree on the development needs of microcontroller instructional teaching module and one respondent stated that he is unsure about the development needs. The respondents provided variety of opinions and insights that could be grouped into three factors. The main factor identified from the responses by 36 respondents $(69.2 \%)$ was that by using the module, teachers would be able to deliver their teaching, together with planning, organisation and engaging with students. The second factor identified from the responses by 11 respondents $(21.2 \%)$ was that teachers felt they were less skilled and less knowledgeable about the subject of electronic design (microcontroller). While the third factor stated by 4 respondents $(7.7 \%)$ are related to practical activities or tutorials included in the module. Respondents indicated that such activities will help students for better understanding about microcontroller and programming. Only one respondent was unsure about the need for development of an instructional module for microcontroller. Figure 2 shows the level of agreement of teachers for microcontroller instructional module development.

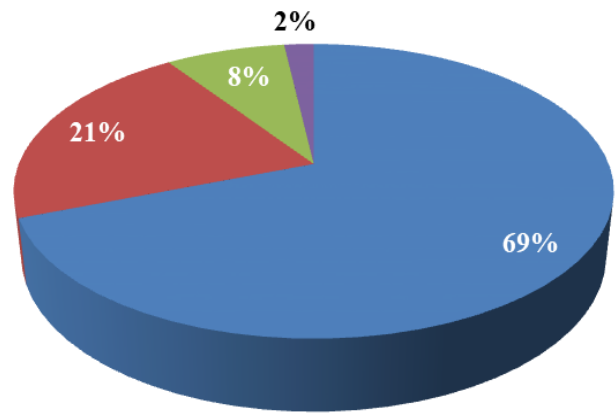

- The instructional module can help teachers to deliver their teaching effectively

The teachers felt they have less skill and less knowledgeable about microcontroller

Agree about practical activities and tutorial include in the module

Figure 2. Teachers level of agreement on the development needs of microcontroller instructional module and their reasons

\subsection{Types of microcontroller and the programming language to be used in the microcontroller} module to be developed

A microcontroller is a fully integrated control device consisting of a central processing unit (CPU), RAM (random access memory), ROM (read only memory) and input and output ports. It is cheap in terms of cost. Microcontroller works to control electronic devices by implementing simple controls based on uploaded programming [16]. Most microcontrollers require only low power because most appliances that involve microcontrollers use the power supply from the battery to operate. Among the electronic devices that use microcontrollers are mobile phones, washing machines, automobiles, cameras and security alarms.

Arduino Uno and Raspberry $\mathrm{Pi}$ are two types of open source microcontroller as shown in Figure 3 [17]. Raspberry Pi Foundation in UK promotes the teaching of basic computer programming in schools using Raspberry Pi [16]. Raspberry $\mathrm{Pi}$ is chosen as a platform to teach programming because it is open source and can be used as a desktop computer $[18,19]$. On the other hand, Arduino Uno needs laptop to run the coding. Only teachers are allowed to bring laptops to class for coding purpose while using Raspberry $\mathrm{Pi}$, a desktop setup can be done by only using other peripheral components such as HDMI monitor, keyboard and mouse attach to Raspberry Pi via USB as shown in Figure 4. The Raspberry Pi low cost kits can immense opportunity to deliver effective, practical, hands-on training [20]. So that, the usage of Raspberry Pi can cater many group of students in class while doing coding and tutorials of microcontroller simultaneously. Raspberry Pi runs on its own Operating System called Raspbian. Raspberry Pi has a built-in software such as Scratch which enables users to program and design animation, game or interesting video. In addition, programmers can also develop script or program using Python language; its main core language in Raspbian

Need analysis for the development of a microcontroller instructional module... (Yusriza Mohamad Yusof) 
operating system [21]. Model B+ is recommended for school learning because it offers more flexibility than model A especially for embedded projects and require low power as well as providing more USB ports compared to Model B [18].

Python is a high level programming language. Using Raspberry Pi, Python can be used interactively using Python interpreter by typing python in a terminal window [22] or using Python 3 IDLE. Figure 5 shows the example of coding in Python 3 IDLE.Its design philosophy provides code readability with color coding and itssyntax allows programmers to express concept in fewer lines of code than would be possible in languages such as $\mathrm{C} / \mathrm{C}++$ [23]. Raspberry $\mathrm{Pi}$ use Python as a main programming language, but also supports other programming languages, such as $\mathrm{C} / \mathrm{C}++$ and Java [24]. The "Pi" in the Raspberry's name derives from "Python" as the main language offered to users [25].

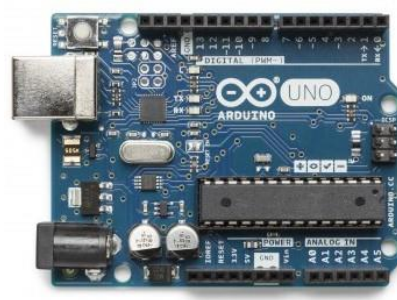

(a)

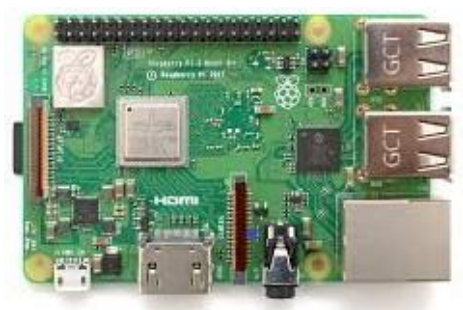

(b)

Figure 3. (a) Arduino Uno and, (b) Raspberry Pi (open source microcontroller board)

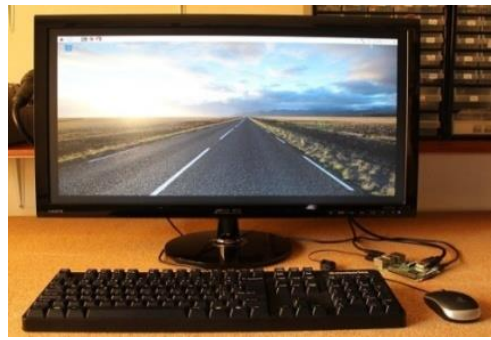

Figure 4. Desktop setup using Raspberry Pi

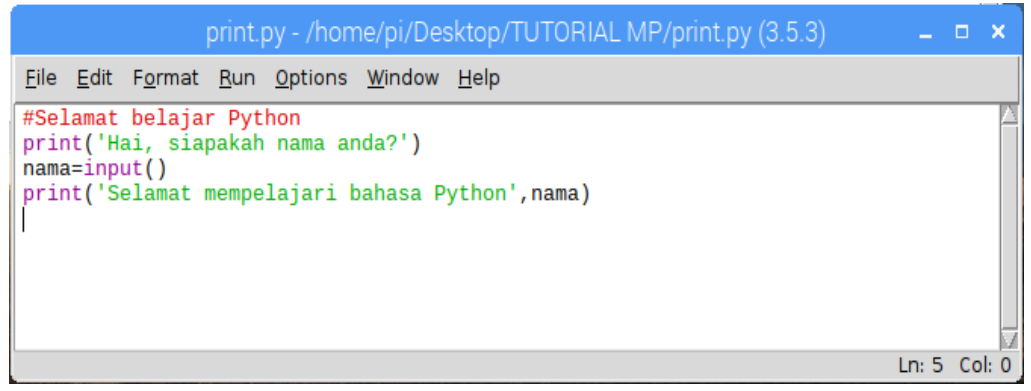

Figure 5. Example of coding in Python 3 IDLE

\section{CONCLUSION}

Need analysis in Phase I of DDR shows that there is a need to develop the Instructional module of microcontroller to enhance programming literacy as well as the usage of digital tools in education. Towards Industries Revolution 4.0, digital education is the innovative way of using digital tools and technologies during teaching and learning, and is often referred to as Technology Enhanced Learning (TEL). Exploring the use of digital technologies gives educators the opportunity to design engaging learning opportunities. Form 2 students learn coding and design electronic circuits using Raspberry Pi 3 B+ microcontroller to complete Electronic Design topic under the subject of Design and Technology (Reka Bentuk danTeknologi-RBT). Learning programming with Raspberry Pi and python languages using the instructional teaching module can help teachers teach more systematically and effectively. The result of Need Analysis (Phase 1) of Design and Development Research (DDR) is important for the $2^{\text {nd }}$ phase of DDR to ensure the instructional module develop will give high impact to programing literacy among students. As proposed in the $2^{\text {nd }}$ phase of DDR, design and development of the instructional module can also include Internet of Things (IoT) application. The IoT inclusion allows students to experience association of things and the web cloud service and hopefully spurs future technology innovations.

\section{ACKNOWLEDGEMENTS}

Funding for this research work was generously supported by grants from National University of Malaysia via Grant Number: GP-K005594. 


\section{REFERENCES}

[1] S. Seiler and R. Sell, "Comprehensive Blended Learning Concept for teaching Micro Controller technology Comprehensive Blended Learning Concept for teaching Micro Controller technology," in Transactions on Edutainment X, 2013.

[2] D. Ibrahim, "A new approach for teaching microcontroller courses to undergraduate students," Procedia-Soc. Behav. Sci., vol. 131, pp. 411-414, 2014.

[3] M. Malaysia Education Blueprint, "Malaysia Education Blueprint 2013-2025," Education, vol. 27, no. 1, pp. 1-268, 2013.

[4] M. Timms et al., Challenges in Stem Learning in Australian Schools Literature and Policy Review,Australian Council for Educational Research, May 2018.

[5] S. Kanemune, S. Shirai, and S. Tani, "Informatics and Programming Education at Primary and Secondary Schools in Japan," Olympiads in Informatics, vol. 11, no. 1, pp. 143-150, 2017.

[6] S. Filippov, N. Ten, I. Shirokolobov, and A. Fradkov, "ScienceDirect Robotics in Secondary School Teaching Robotics in Secondary School," IFAC-PapersOnLine, vol. 50, no. 1, pp. 12155-12160, 2017.

[7] E. H. M. Shahali, L. Halim, M. S. Rasul, K. Osman, and M. A. Zulkifeli, "STEM learning through engineering design: Impact on middle secondary students' interest towards STEM," Eurasia J. Math. Sci. Technol. Educ., vol. 13, no. 5, pp. 1189-1211, 2017.

[8] K. Jayarajah, R. M. Saat, R. Amnah, and A. Rauf, "A Review of Science, Technology, Engineering \& Mathematics (STEM) Education Research from 1999-2013: A Malaysian Perspective,” Eurasia Journal of Mathematics, Science \& Technology Education, vol. 10, no. 3, pp. 155-163, 2014.

[9] A. Merkouris, K. Chorianopoulos, and A. Kameas, "Teaching programming in secondary education through embodied computing platforms: Robotics and wearables," ACM Trans. Comput. Educ., vol. 17, no. 2, 2017.

[10] R. C. Richey and J. D. Klein, Design and Development reseacrh Methods, Strategies and issues, Routledge, 2007.

[11] M. Borrego, E. P. Douglas, and C. T. Amelink, "Quantitative, qualitative, and mixed research methods in engineering education,” J. Eng. Educ., vol. 98, no. 1, pp. 53-66, 2009.

[12] O. Talib, SPSS Analisis Kuantitatif Untuk Penyelidik Muda, MPWS Rich Publ., 2015.

[13] Ghazali \& Sufean, "Metodologi Penyelidikan Dalam Pendidikan: Amalan Dan Analisis Kajian", Univ. Malaya, 2016

[14] J. R. Fraenkel, N. E. Wallen, and H. H. Hyun, "How to Design and Evaluate Research in Education", 8th Edition, 2012.

[15] L. Cohen, "Research Methods in Education", Routledge, 2002.

[16] A. Khanum and V. Rekha, "An enhanced security alert system for smart home using IOT," Indonesian Journal of Electrical Engineering and Computer Science, vol. 13, no. 1, pp. 27-34, 2019.

[17] L. M. Herger and M. Bodarky, "Engaging students with open source technologies and Arduino," in ISEC 2015-5th IEEE Integrated STEM Education Conference, 2015.

[18] A. N. Azlina, A. B. Zanariah, and Y. Faridah, "Intelligent home automated system," Indonesian Journal of Electrical Engineering and Computer Science, vol. 15, no. 2, pp. 733-742, 2019.

[19] J. Cicolani, Beginning Robotics with Raspberry Pi and Arduino, Apress, 2018.

[20] N. S. Yamanoor and S. Yamanoor, "High Quality, Low Cost Education with the Raspberry Pi," in IEEE Global Humanitarian Technology Conference (GHTC), 2017.

[21] C. W. Zhao, J. Jegatheesan, and S. C. Loon, "Exploring IOT Application Using Raspberry Pi," Int. J. Comput. Networks Appl., 2015.

[22] S. Kelly, "Introducing Python," in Python, PyGame, and Raspberry Pi Game Development, Berkeley, CA: Apress, 2019.

[23] A.A.Pawar and J.S.Rangole, "Review paper on Implementation 'Raspberry Pi and wifi based home automation server,"” Int. J. Adv. Eng. Res. Dev., vol. 3, no. 2, pp. 84-87, 2016.

[24] X. Zhong and Y. Liang, "Raspberry Pi: An Effective Vehicle in Teaching the Internet of Things in Computer Science and Engineering," Electronics, 2016.

[25] M. Kölling, "Educational programming on the Raspberry Pi," Electron., 2016. 